\begin{tabular}{|c|c|c|}
\hline \multirow{3}{*}{$\begin{array}{r}\text { Case Reports in } \\
\text { Gastroenterology }\end{array}$} & \multirow{2}{*}{\multicolumn{2}{|c|}{ Case Rep Gastroenterol 2013;7:438-441 }} \\
\hline & & \\
\hline & $\begin{array}{l}\text { DOI: 10.1159/000355880 } \\
\text { Published online: October 9, } 2013\end{array}$ & $\begin{array}{l}\text { (c) } 2013 \text { S. Karger AG, Basel } \\
\text { 1662-0631/13/0073-0438 } \$ 38.00 / 0 \\
\text { www.karger.com/crg }\end{array}$ \\
\hline & \multicolumn{2}{|c|}{$\begin{array}{l}\text { This is an Open Access article licensed under the terms of the Creative Common } \\
\text { Attribution-NonCommercial } 3.0 \text { Unported license (CC BY-NC) (www.karger.com/OA } \\
\text { license), applicable to the online version of the article only. Distribution permitted for non } \\
\text { commercial purposes only. }\end{array}$} \\
\hline
\end{tabular}

\title{
Ameboma: A Colon Carcinoma-Like Lesion in a Colonoscopy Finding
}

\author{
Chung-Cheng Lin ${ }^{a}$ Kuo-Yao Kao ${ }^{b}$ \\ ${ }^{a}$ Division of Gastroenterology, Department of Internal Medicine, Pingtung Hospital, \\ Pingtung, and ${ }^{b}$ Division of General Surgery, Department of Surgery, Shin Kong Wo Ho-Su \\ Memorial Hospital, Taipei, Taiwan
}

\section{Key Words}

Ameboma $\cdot$ Colon carcinoma-like lesion · Colonoscopy

\begin{abstract}
Ameboma is a rare complication of amebic colitis presenting as a mass of granulation tissue with peripheral fibrosis and a core of inflammation related to amebic chronic infection. The initial presentations are usually obstruction and low gastrointestinal bleeding. The most common sites are the ascending colon and the cecum. It may mimic colon carcinoma, Crohn's disease, carcinoma of the colon, non-Hodgkin's lymphoma, tuberculosis, fungal infection, AIDS-associated lymphoma and Kaposi's sarcoma in colonoscopy findings. The therapeutic strategy should be combined with antibiotics for invasive dysentery and eradication of luminal cysts.

(c) 2013 S. Karger AG, Basel
\end{abstract}

\section{Introduction}

Entamoeba histolytica infection is common in developing countries due to the poor environment. In developed countries, this amebic infection is also an important issue for travelers in highly epidemic countries or in the immunocompromised population, including patients with AIDS or receiving organ transplantation. The most common clinical symptoms of amebic infection are amebic colitis, which has various symptoms, and amebic liver abscess. The best current estimate is that E. histolytica causes 34-50 million symptomatic infections annually worldwide, resulting in 40,000-100,000 deaths each year [1]. Worldwide, approximately 40-50 million people develop colitis or extraintestinal disease annually with 40,000 deaths [2]. Most patients with E. histolytica infection are asymptomatic, comprising about $90 \%$ of those infected [3]. Ameboma is a rare complication of amebic colitis and may caused related intraluminal granulation tissues that mimic colon carcinoma [4]. It

Dr. Kuo-Yao Kao

Division of General Surgery, Department of Surgery

Shin Kong Wo Ho-Su Memorial Hospital

Taipei (Taiwan)

E-Mail surrender45@hotmail.com 
may result in low gastrointestinal bleeding and bowel obstruction. We present a 45 -year-old male with intermittent bloody stool and right lower abdominal pain for about 1 month. A colon carcinoma-like mass was noted in his colonoscopy finding.

\section{Case Report}

The 45-year-old male patient denied any prior systemic disease. He had been buying and selling merchandise in Indonesia for 18 years. According to the patient's statement, he had suffered from intermittent bloody stool for nearly 1 month. He also denied any history of hemorrhoids and had not suffered from the same episode before. The increased bloody stool amount was first noted 4 days previously (on February 14) and subsequently about 5-6 times per day with a volume of $20-30 \mathrm{ml} /$ time. He had also been suffering from abdominal pain over the periumbilical area, especially on the right site, for about 1 month. Intermittent fever was also during that week. He had eaten raw food with sashimi and uncooked eggs about 1 month previously. According to his statement, the locals clean the dishes with groundwater.

Due to the above problem, he was taken to our emergency room. Colonoscopy was also done at the emergency room and showed multiple small polyps over the terminal ileum and multiple indurated ulcerations over the rectum and cecum (fig. 1). A mild elevation in C-reactive protein and erythrocyte sedimentation rate were noted. Normocytic anemia was also noted and suspected to be related to the bloody stool. Bedside abdominal echography showed no obvious liver abscess. Pathologic examination was also performed and showed chronic inflammatory infiltrate of lymphoplasma cells, eosinophils and neutrophils in the edematous fibrous lamina propria. Focal aggregations of amoeba trophozoites were demonstrated by periodic acid-Schiff stain (fig. 2). Ameboma was diagnosed and metronidazole was prescribed for invasive dysentery for 14 days. Additionally, iodoquinol was also prescribed for luminal infection and to prevent colonization. After 3 days of treatment the symptoms, including bloody stool and fever, had resolved. Follow-up colonoscopy showed much improvement 4 months post treatment and complete remission after 8 months (fig. 3).

\section{Discussion}

The risk of contracting amebic colitis includes people living in endemic regions (India, Africa, Mexico and parts of Central and South America), immigrants from or travelers to endemic regions, male homosexuals and institutionalized persons. In addition, malnourished patients, infants, elderly, pregnant women and patients receiving glucocorticoids may be at increased risk for fulminant disease. In our case, the patient lived in an endemic region (India) and his dishes were cleaned with uncooked water. Combined with the symptom of bloody stool for about 1 month, amoebic colitis should be differentially diagnosed. Biopsy provided a diagnosis of ameboma. Other tests, including antigen detection assays, are the best current means for diagnosing intestinal amebiasis since they are sensitive, specific, rapid, easy to perform and distinguish E. histolytica from Entamoeba dispar infections. Antibody measurements are also available but remain positive for years. Stool specimens for microscopy are far less sensitive than antigen detection and cannot differentiate between species [5].

Ameboma is a mass of granulation tissue with peripheral fibrosis and a core of inflammation related to amebic chronic infection usually found in the cecum and ascending colon. 
In the colonoscopy finding, ulcerative mass with ulceration and mucosal change over the rectum, ascending colon and cecum, Crohn's disease, carcinoma of the colon, non-Hodgkin's lymphoma, tuberculosis, fungal infection, AIDS-associated lymphoma and Kaposi's sarcoma are considerations of differential diagnosis. Ameboma was considered in the first place because of the patient's young age, multiple lesions in the ascending colon, cecum, and rectum, and the fact that the edge of the ulcerative mass was not abrupt as in malignancy. Sometimes, ameboma is treated as Crohn's disease with glucocorticoids, which leads to fulminant colitis. The major complications of ameboma include perforation, obstruction, intussusception, anorectal fistula and appendicitis [6]. The treatment of ameboma includes antibiotics and agents for eliminating intestinal cysts. Metronidazole both eliminates the invading trophozoites and eradicates intestinal carriage of the organism. The cure rate is approximately $90 \%$ [2]. Furthermore, tinidazole, ornidazole and nitazoxanide are alternative therapies $[7,8]$.

After metronidazole treatment for invasive amoebic dysentery, agents for the cure of luminal infection with paromomycin, the second-line agent diloxanide furoate or diiodohydroxyquinoline (iodoquinol) are necessary due to persistent parasites in $40-60 \%$ of patients $[9,10]$. Therefore, metronidazole and paromomycin should not be given at the same time owing to the side effects of paromomycin, the most common being diarrhea, and because it is difficult to differentially diagnose this from the patient's response to treatment. After combination therapy, the cure rates are approximately 86-90\% [9]. Follow-up stool examinations are required after completion of the therapy since no regimen is completely effective. In this case, the initial presentation was intermittent bloody stool with abdominal pain. The contamination way was through contaminated dishes, which are washed with groundwater in the high-prevalence region of Indonesia. The sites of ameboma were also compatible with the most common sites of amebic colitis, including the cecum, ascending colon and terminal ileum. The appearance was that of carcinoma-like lesions. The therapeutic strategy combined metronidazole for the invasive amebic dysentery and iodoquinol for the luminal infection. After treatment, the symptoms dramatically improved and there was complete resolution after 8 months shown by follow-up colonoscopy. Vaccination may be considered as a priority for people traveling to high-prevalence countries and at high risk for amoebic infection.

\section{References}

1 Walsh JA: Problems in recognition and diagnosis of amebiasis: estimation of the global magnitude of morbidity and mortality. Rev Infect Dis 1986;8:228-238.

-2 Li E, Stanley SL Jr: Protozoa. Amebiasis. Gastroenterol Clin North Am 1996;25:471-492.

-3 Gathiram V, Jackson TF: A longitudinal study of asymptomatic carriers of pathogenic zymodemes of Entamoeba histolytica. S Afr Med J 1987;72:669-672.

-4 Haque R, Huston CD, Hughes M, Houpt E, Petri WA Jr: Amebiasis. N Engl J Med 2003;348:1565-1573.

-5 Bracha R, Diamond LS, Ackers JP, Burchard GD, Mirelman D: Differentiation of clinical isolates of Entamoeba histolytica by using specific DNA probes. J Clin Microbiol 1990;28:680-684.

6 Ash J, Spitz S: Pathology of Tropical Diseases. Philadelphia, Saunders, 1945.

7 Misra NP, Gupta RC: A comparison of a short course of single daily dosage therapy of tinidazole with metronidazole in intestinal amoebiasis. J Int Med Res 1977;5:434-437.

-8 Singh G, Kumar S: Short course of single daily dosage treatment with tinidazole and metronidazole in intestinal amoebiasis: a comparative study. Curr Med Res Opin 1977;5:157-160.

-9 McAuley JB, Juranek DD: Paromomycin in the treatment of mild-to-moderate intestinal amebiasis. Clin Infect Dis 1992;15:551-552.

10 Blessmann J, Tannich E: Treatment of asymptomatic intestinal Entamoeba histolytica infection. N Engl J Med 2002;347:1384. 
Lin et al.: Ameboma: A Colon Carcinoma-Like Lesion in a Colonoscopy Finding

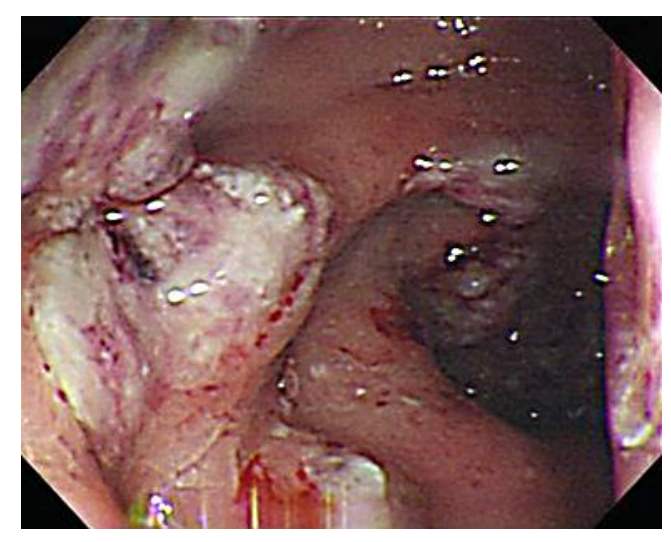

Fig. 1. Colonoscopy showed multiple small polyps over the terminal ileum and multiple indurated ulcerations over the rectum and cecum.

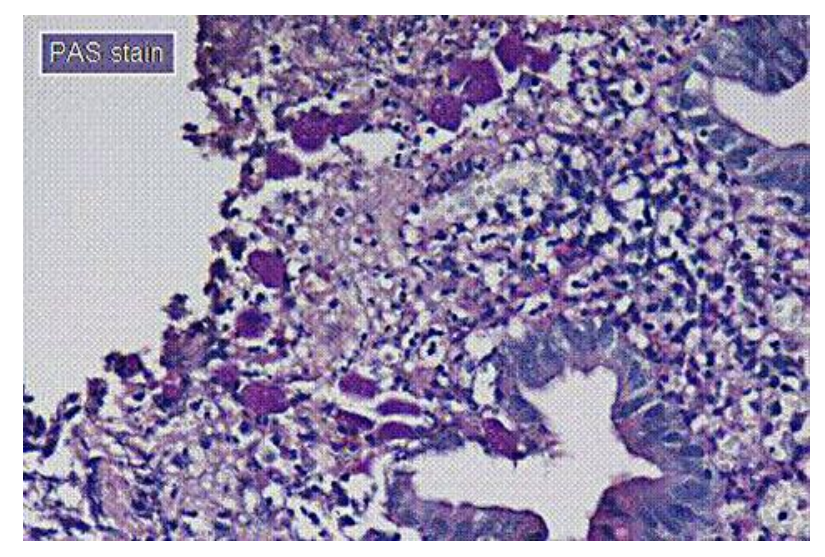

Fig. 2. Focal aggregations of amoeba trophozoites were demonstrated by periodic acid-Schiff stain.

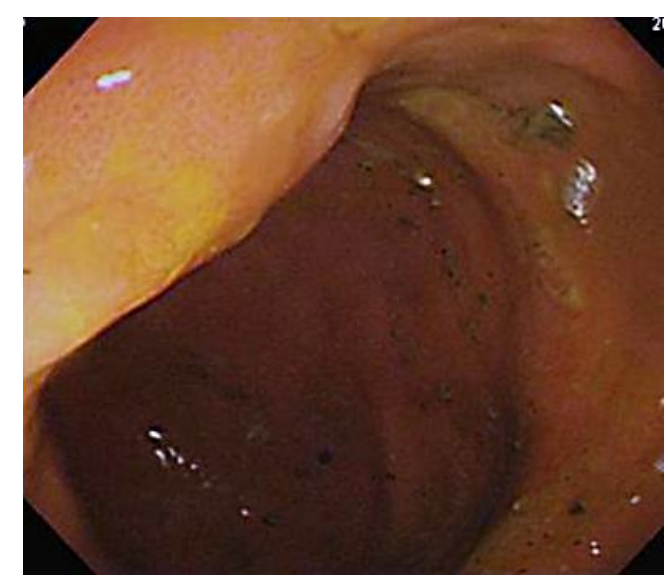

Fig. 3. Follow-up colonoscopy 8 months post treatment showed complete remission. 